This is a pre-copy-editing, author-produced PDF of an article accepted for publication in Medicine \& Science in Sports \& Exercise following peer review. The definitive publisher-authenticated version Cathcart, Andrew J., Murgatroyd, Scott R., McNab, Alison, Whyte, Laura J and Easton, Chris (2008) The thermoregulatory effect of consuming a beverage containing protein during exercise, 2008, 40(5)S74 is available online at: http://dx.doi.org/10.1249/01.mss.0000321770.01371.a9 


\title{
THE THERMOREGULATORY EFFECT OF CONSUMING A BEVERAGE CONTAINING PROTEIN DURING EXERCISE
}

\author{
Andrew J. Cathcart ${ }^{1}$, Scott Murgatroyd ${ }^{2}$, Alison $\mathrm{McNab}^{1}$, Laura J. Whyte ${ }^{1}$, Chris \\ Easton ${ }^{1} .{ }^{1}$ International Centre for East African Running Science (ICEARS), \\ University of Glasgow, Glasgow, UK. ${ }^{2}$ Centre for Sport and Exercise Sciences, \\ University of Leeds, Leeds, UK.
}

Lab based studies have demonstrated that adding a small quantity of protein to a typical CHO-electrolyte beverage is beneficial, e.g. improved recovery from strenuous exercise (St. Laurent et al. Med Sci Sports Exerc 38: S340, 2006) and increased thermoregulatory capacity (Goto et al. FASEB J. 21: 919, 2007). However, no study has investigated whether this will actually aid in constraining the rise in core temperature during strenuous exercise in the heat and, importantly, whether these physiological changes can affect performance in a real-life sporting event. PURPOSE: To determine the effect of consuming a standard CHO-electrolyte beverage containing a small quantity of protein during eight days of strenuous competition in a hot environment. METHODS: Twenty eight cyclists participating in the TransAlp eight day mountain bike stage race were recruited. They were assigned to fitness matched placebo (PLA: $76 \mathrm{~g} \mathrm{CHO,} \mathrm{460mg} \mathrm{Na}{ }^{+}$and $120 \mathrm{mg} \mathrm{K}^{+}$: all.1 ${ }^{-1}$ ) or protein (PRO: 20g Protein, $73 \mathrm{~g} \mathrm{CHO}, 552 \mathrm{mg} \mathrm{Na}^{+}$and $144 \mathrm{mg} \mathrm{K}^{+}$: all $\cdot \mathrm{l}^{-1}$ ) groups based on $\dot{V} O_{2}$ peak (submaximal cycle ergometer prediction). Immediately $(<1 \mathrm{hr})$ before and after each stage, core temperature, urine osmolality, creatine kinase concentration $[\mathrm{CK}]$, rating of muscle soreness and body mass were measured. Heart rate throughout competition and performance were recorded. RESULTS: Ambient temperature ranged from $29^{\circ} \mathrm{C}$ to $40^{\circ} \mathrm{C}$ during the race. There was no significant difference in $[\mathrm{CK}]$ between groups before the event (PRO: $130.9 \pm 82.8$ vs. PLA: $130.6 \pm 82.6$ ). Although $[\mathrm{CK}]$ was substantially elevated during the race, the rise was not different between the groups $(p=0.36)$. Both groups commenced the race with similar urine osmolalities (PRO: $753.5 \pm 210.1$ vs. PLA: $753.7 \pm 185.1 \mathrm{mOsmol}$ ), this increased significantly in both groups (PRO: $p=0.017$; PLA $p=0.044$ ) although the rise was more marked in PRO (PRO vs. PLA $p=0.002$ ). Core temperature was not significantly different between groups prior to the start of stage 1 (PRO: $37.0 \pm 0.36$ vs. PLA: $36.9 \pm 0.39^{\circ} \mathrm{C}$ ) but was significantly lower post exercise throughout the race in PRO (PRO: $37.7 \pm 0.32$ vs. PLA: $\left.38.0 \pm 0.32{ }^{\circ} \mathrm{C}\right)(p<0.001)$. Total race time was significantly shorter in PRO (2326 vs. 2591 minutes; $p=0.04)$ CONCLUSIONS: Core temperature was significantly lower and performance was significantly better in PRO despite no difference in muscle damage.

This work was supported in part by High5 Ltd, Leicester, UK. 